\section{Itinerários terapêuticos em situações de pobreza: diversidade e pluralidade}

\author{
Therapeutical itineraries in poverty \\ situations: diversity and plurality
}

Tatiana Engel Gerhardt 1

\section{Introdução}

The low-income population's practices and strategies for coping with daily problems, especially in relation to the search for health care, are analyzed by means of therapeutic itineraries. To unveil this population's coping strategies in relation to their health-disease process means identifying the individual and collective strategies and the meaning of these social dynamics related directly or indirectly to health. The search for treatment is described and analyzed here in relation to socio-cultural practices in terms of the paths chosen by individuals in the attempt to solve their health problems. The study thus indicates an interdisciplinary and multi-methodological and conceptual approach relating concepts of practices, strategies, and health and life situations. The point of departure is that ways of coping with health problems require an understanding of the strategies developed in a process of (re)appropriation and (re)construction of knowledge. It is equally important to identify social support networks and individual capacity to mobilize such resources. The recognition of these practices allows (re)directing actions in collective health.

Delivery of Health Care; Socioeconomic Factors; Problem Solving
As práticas e estratégias da população de baixa renda no enfrentamento de seus problemas cotidianos, sobretudo em relação à procura de cuidados em saúde, são aqui analisadas através dos itinerários terapêuticos. A relação entre itinerários terapêuticos e pobreza é bastante relevante no campo da Saúde Coletiva, em especial no contexto brasileiro, marcado pela desigualdade social e diversidade cultural que se reflete na busca do cuidado. O termo itinerário terapêutico é aqui utilizado como sinônimo de busca de cuidados terapêuticos e procura descrever e analisar as práticas individuais e sócio-culturais de saúde em termos dos caminhos percorridos por indivíduos pertencentes a camadas de baixa renda, na tentativa de solucionarem seus problemas de saúde. A partir do surgimento de um ou mais sintomas físicos ou psíquicos e de seu reconhecimento como tal, o indivíduo se encontra frente a uma rede complexa de escolhas possíveis 1 . Os processos de escolha, avaliação e aderência a determinadas formas de tratamento são complexos e difíceis de serem apreendidos se não for levado em conta o contexto dentro do qual o indivíduo está inserido, sobretudo frente à diversidade de possibilidades disponíveis (ou não) em termos de cuidados em saúde para as populações de baixa renda.

Para se compreender a saúde dos indivíduos e a forma como eles enfrentam a doença torna- 
se necessário analisar suas práticas (itinerários terapêuticos), a partir do contexto onde elas tomam forma, pois cada contexto possui características próprias e especificidades É nesse contexto que acontecem os eventos cotidianos (econômicos, sociais e culturais) que organizam a vida coletiva, que enquadram a vida biológica e é dentro dele que os indivíduos evoluem ao mesmo tempo em que seu corpo, seus pensamentos, suas ações, são formatados por esse espaço social. Por outro lado, é necessário também considerar os indivíduos como atores sociais, definidos ao mesmo tempo por esse espaço social no qual se inserem e pela consciência de agir sobre esse espaço 2.

Assim, "é preciso hoje reconhecer que a natureza das formas de procura de cuidados é variada e complexa, que se diferencia de um indivíduo a outro, que pode variar em um mesmo indivíduo de um episódio de doença a outro $e$ que a procura de cuidados está sujeita a questionamentos repetidos em cada uma das etapas do processo de manutenção da saúde. De fato, a natureza e a seqüência dos encaminhamentos na procura de cuidados são determinadas por uma série de variáveis situacionais, sociais, psicológicas, econômicas e outras. A procura de cuidados está condicionada tanto pelas atitudes, os valores e as ideologias quanto pelos perfis da doença, o acesso econômico e a disponibilidade de tecnologias" 1 (p. 330).

Desta forma, "o desafio lançado pela multiplicidade de escolhas, de condutas, de tratamentos adotados simultaneamente, ou em série, por um mesmo indivíduo, não pode ser apreendido por uma abordagem centrada no sujeito, estritamente individual, interacionista e que retém somente a estratégia de escolha a fim de chegar na sua lógica. Isso conduziria a uma interpretação cognitiva que negligencia a incorporação de cuidados no social. Pois o pluralismo terapêutico é amplamente o resultado de relações sociais que transcendem as condutas individuais. Elas exercem pressão sobre as escolhas; elas orientam, favorecem ou penalizam as decisões" 3 (p. 7).

Fassin 4,5 demonstrou, a partir de estudos na África de diversos itinerários terapêuticos, que "os caminhos percorridos pelo doente à procura de diagnóstico e tratamento surge como resultado de múltiplas lógicas, de causas estruturais (sistemas de representações da doença, posição do indivíduo na sociedade) e de causas conjunturais (modificação da situação financeira, conselho de um vizinho) que torna em vão toda tentativa de estrita formalização. (...) Portanto, da necessidade de resituar a seqüencia de eventos contextuais da procura de cuidados em relação à complexidade dos fatores sociais que ela implica" 4 (p. 118).

Já no Brasil, Alves \& Souza 6 desenvolveram uma importante revisão da literatura sócio-antropológica sobre o processo de escolha e avaliação de tratamento para problemas de saúde, enfocando as diferentes abordagens e interpretações e o próprio conceito de itinerário terapêutico. Segundo os autores "é necessário que os estudos sobre itinerário terapêutico possam 'descer' ao nivel dos procedimentos usados pelos autores na interpretação de suas experiências e delineamento de suas ações sem, contudo, perder o domínio dos macroprocessos sócio-culturais" 6 (p. 132). Alves \& Souza, baseando-se em Rabelo 7 , propõem que não existe um padrão único e pré-definido no processo de busca terapêutica e que o itinerário é um processo complexo não podendo ser reduzido "a generalidades que procedem pela descoberta de leis que ordenam o social. A recorrência simultânea a vários tratamentos e a existência de visões discordantes - e até mesmo contraditórias - sobre a questão terapêutica evidenciam que tanto a doença como a cura são experiências intersubjetivamente construídas, em que o paciente, sua família e aqueles que vivem próximos estão continuamente negociando significados" 6 (p. 136). Nos estudos sobre itinerários terapêuticos é importante, portanto, que não se desconheça essa realidade, tal como o fizeram as teorias de caráter nomológico-dedutivo que procuraram explicar as ações individuais baseadas em argumentos previamente estabelecidos. "Na interpretação de um determinado processo de escolha terapêutica é preciso que se apresente o sujeito desse processo como alguém que compartilha com outros um estoque de crenças e receitas práticas para lidar com o mundo, receitas estas que foram adquiridas (e ampliadas, reformuladas ou mesmo descartadas) ao longo de uma trajetória biográfica singular. Porém, reconhecer a existência de estruturas sociais não significa dizer que elas sejam determinantes das ações humanas. Uma coisa é o significado objetivo de um dado fenômeno sócio-cultural definido por um padrão institucionalizado; outra coisa, o modo particular como o indivíduo define a sua situação no seio dele" 6 (p. 133). Em estudo anterior, Alves 8 já evidenciava o complexo processo de busca terapêutica com base na experiência da enfermidade dos indivíduos como sendo uma expressão não antagônica das dimensões cognitivas (individuais) e sociais (coletivas).

Tais considerações teóricas são fundamentais para o estudo do itinerário terapêutico, permitindo-nos pôr em relevância dois aspectos 
essenciais e interligados: as definições de situação e a natureza das relações intersubjetivas no processo de tomada de decisão. Daí a necessidade de reformular não só o próprio conceito de itinerário terapêutico, como propõem Alves \& Souza 6, mas também a forma de abordar o tema, atendendo ao desafio, tanto para a Antropologia como para a Saúde Coletiva, de conciliar o individual e o coletivo, o material e o imaterial.

Desta forma, foi em Paranaguá, Paraná, Brasil, que a problemática do estudo centrada na relação entre situações de vida, pobreza e saúde, buscou uma ilustração concreta da diversidade e complexidade na procura de cuidados terapêuticos por indivíduos de baixa renda. Esse estudo, parte de uma tese de Doutorado, se desenvolveu no âmbito do programa interdisciplinar de pesquisa Espaço Urbano, Situações de Vida e Saúde: O Caso de Paranaguá, do Doutorado em Meio Ambiente e Desenvolvimento da Universidade Federal do Paraná e da Université de Bordeaux 2, que abordou as relações entre desigualdades sociais e de saúde 9 .

A situação observada em Paranaguá é a de uma cidade de porte médio (115 mil habitantes em 1997), com densidade humana elevada, rápido crescimento demográfico $(4 \%$ ao ano desde 1940) e com problemas importantes de urbanismo e emprego. A cidade apresentou nos últimos 40 anos um quadro de crescimento populacional acelerado em que as dinâmicas de ocupação territorial não foram acompanhadas da correspondente expansão da infra-estrutura de abastecimento de água, esgoto, coleta de lixo, pavimentação e energia elétrica, e ampliação da cobertura de serviços essenciais, como educação e saúde. O rápido crescimento urbano, decorrente de migrações rural-urbano e urbano-urbano e de taxas de crescimento vegetativo ainda elevadas, acarretou não só transformações no meio físico, mas também transformações sociais. Essas transformações na sociedade não ocorreram de forma homogênea no espaço urbano, originando uma diversificação que compõe o atual quadro de heterogeneidades espaciais e desigualdades sociais 10 .

O estado de saúde da população avaliado no seu conjunto pelos dados de mortalidade e morbidade, revela várias situações: mudança gradativa do perfil de mortalidade em que começam a aparecer nitidamente os problemas do envelhecimento populacional, porém ainda persistem problemas revelados pelas altas taxas de mortalidade infantil e materna; outra situação é a persistência de problemas infecciosos e parasitários, sobretudo na população infantil 11; na assistência à saúde, embora pareça ter ocorrido um aumento do acesso da população aos serviços básicos, questões importantes como a assistência adequada à gestação e ao parto, não parecem ser extensivas a toda a população. Essas situações retomam o problema das disparidades em saúde não só no sentido de constatá-las, mas de como enfrentá-las e superá-las num contexto de grandes heterogeneidades espaciais e desigualdades sociais.

O tema das relações entre itinerários terapêuticos e pobreza está inserido neste contexto local particular. As informações sobre a situação da cidade como um todo e as particularidades intra-urbanas, obtidas ao longo das pesquisas interdisciplinar e disciplinar, constituem o pano de fundo dos questionamentos sobre a busca de cuidados terapêuticos dos indivíduos com condições de vida precárias 2 . O estudo foi centrado na capacidade desses indivíduos em mobilizar recursos ou formular estratégias de enfrentamento de seus problemas cotidianos e de suas necessidades básicas, e guiaram as hipóteses de pesquisa, tais como: a capacidade de mobilizar recursos e formular estratégias é modelada pela história de vida, pela experiência vivida pelos indivíduos e suas famílias, pela dinâmica individual que resulta disto ou até mesmo pela personalidade individual; cada um interpreta e constrói sua própria situação de vida, e estas situações variam nas diferentes zonas da cidade e nos diferentes estratos sócioeconômicos.

A vida na cidade, de forma geral, apresenta hoje uma disparidade crescente que divide as diferentes categorias sociais, sobretudo em termos de emprego, renda, moradia, meio físico, alimentação e saúde. A saúde constitui um elemento central e essencial para a reprodução dos grupos humanos, representando um campo propício à avaliação objetiva do quadro de vida urbano, nos seus componentes materiais e sociais, e do que ele pode ocasionar sobre o corpo físico dos indivíduos, constituindo assim, no campo antropológico, um ângulo de análise da sociedade, um campo revelador do seu funcionamento. As estratégias desenvolvidas pelos indivíduos e os discursos que as acompanham são elaborados a partir de instituições, representações coletivas e relações sociais que os indivíduos reinterpretam, recompõem, em função das situações e restrições existentes. A abordagem das dinâmicas sociais requer assim que se busque entender a articulação entre o social e o cultural. Ela exige também que seja explorada a relação dialética que sempre se estabelece, na construção das realidades sociais, entre as determinações de caráter estrutural e coletivo e o papel inovador das 
atuações individuais - o que representa outro desafio científico 11 .

Para levar em conta as dinâmicas, os conflitos, as contradições, nos distanciamos da visão segundo a qual as práticas e representações individuais seriam totalmente impostas pelo contexto material, social e cultural de sua existência. O desafio consiste em conciliar a atenção legítima dada ao ator individual com a preocupação de identificar o que, no seu universo cultural (complexo, diversificado e em transformação), forma e informa as suas decisões e suas escolhas. Este campo é particularmente fecundo para a abordagem da esfera pública e particular, do individual e coletivo, na medida em que saúde e doença refletem-se no corpo dos indivíduos. O tema das relações entre itinerários terapêuticos e pobreza é pertinente e susceptível de contribuir para abordar as relações entre o individual e o coletivo.

A partir destas considerações, foi em termos de situações de vida que foram abordadas essas questões. Esta noção, central a este estudo, mostrou-se pertinente, pois associa a utilização que os atores sociais fazem de suas condições materiais e imateriais, em função das percepções que eles constroem dos problemas e dificuldades aos quais estão submetidos, recompondo e reinterpretando estes problemas. Além disso, tem o mérito de permitir o diálogo entre o que, na existência de um indivíduo - ou de um grupo - provém de fatores contextuais problemáticos, sejam eles materiais, sociais ou culturais, e as interpretações e combinações que o indivíduo faz em função de suas próprias percepções, de seus objetivos e de sua capacidade em formular um projeto de vida. É justamente nesse contexto dinâmico que é realizada a hierarquia dos problemas. A noção de situações de vida assim definida permite conciliar a existência de fatores objetivos de vulnerabilidade (condições materiais e sociais de vida) e a ação do sujeito como intérprete do real, e se torna um instrumento interessante para a compreensão da vulnerabilidade 2 . É desta forma que foram pensados e analisados os itinerários terapêuticos na cidade de Paranaguá, procurando revelar não somente a diversidade e a pluralidade das escolhas, mas evidenciando as estratégias complexas dos atores sociais, a partir do universo sócio-cultural (individual e coletivo) em que se inserem e, sobretudo, do papel dos indivíduos enquanto sujeitos sociais (material e imaterial).

\section{Materiais e métodos}

Num esforço de compreensão das diferentes dimensões do fenômeno de urbanização, a conseqüência metodológica destas asserções é a existência de complementaridade entre as análises das várias formas de heterogeneidades: espaciais, sócio-econômicas, sanitárias. O alicerce teórico da interdisciplinaridade, aplicado ao estudo de Paranaguá 2,9,11,12, parte da construção de uma problemática comum entre as diferentes disciplinas participantes (epidemiologia, antropologia, economia, geografia), onde cada uma permanece como "locus" fundamental de produção do saber, podendo dialogar através de espaços construídos que permitam tal colaboração, a saber: a escolha de uma área geográfica e de um problema de pesquisa comum.

Desta forma, o campo empírico de Paranaguá foi explorado em diferentes momentos (níveis de análise) e de diferentes formas: por operações coletivas de pesquisa que visaram a construir um diagnóstico da situação global da cidade e viabilizar o diálogo entre pesquisadores da equipe, graças à construção de instrumentos comuns de definição e de descrição das diferenciações do espaço urbano do ponto de vista espacial (zoneamento) e sócio-econômico (estratificação social); por operações individuais (disciplinares), pesquisas epidemiológica e antropológica.

O primeiro nível de análise compreendeu um zoneamento (por meio da cartografia) da cidade que caracterizou as heterogeneidades espaciais 9,10, a partir das seguintes variáveis: história do crescimento espacial da cidade, funções urbanas e ofertas de serviços, densidade demográfica, nível sócio-econômico e de saneamento. No segundo nível de análise, foi elaborada uma estratificação social da população (análise multivariada), que permitiu a descrição das disparidades internas de cada zona 13 . As variáveis utilizadas foram: tipo de moradia, número de moradores $/ \mathrm{m}^{2}$ do domicílio, escolaridade do chefe de família, número de banheiros, bens de consumo e serviços (máquina de lavar roupa, vídeo cassete, freezer, carro, televisão em cores, rádio, empregada doméstica). Após a elaboração da estratificação social, as duas categorias (espaço e a estratificação) foram confrontadas 13 .

O grande desafio metodológico para o estudo antropológico foi o de trabalhar com vários níveis de análise, em escalas sucessivas de aproximação da realidade, por meio de instrumentos e categorias de análise que permitiram ir além da visão global da cidade. 
Dentro desse quadro geral, o acompanhamento e análise dos itinerários terapêuticos centrou-se nas famílias pertencentes a camadas de baixa renda, mas com capacidades diferentes de mobilização de recursos sociais e residentes em duas zonas privilegiadas pela pesquisa - Ilha de Valadares e Franjas 2. Para selecionar as famílias com situações de vida diferentes (materiais e sociais), capazes de modelar de forma positiva ou negativa suas vidas cotidianas, elaborou-se uma tipologia permitindo relacionar as estratégias cotidianas e o quadro geral da cidade. Foram utilizados dois indicadores: as condições de vida materiais (estratificação social) e as condições sociais de existência. Este último indicador compreendeu as possibilidades de mobilização de recursos sociais em termos de relações sociais, e foi construído com base em variáveis indicadoras das redes sociais nas quais os indivíduos estão inseridos 13:

- Tipo de estrutura familiar residencial capaz de mobilizar recursos intrafamiliares: famílias com poucas condições de mobilização de recursos intrafamiliares (pessoas que moram sozinhas e/ou pessoas sem estrutura familiar + famílias monoparentais + famílias nucleares com filhos menores de 15 anos); famílias com condições de mobilização de recursos intrafamiliares (famílias nucleares com filhos acima de 15 anos, famílias extensas);

- Existência de laços familiares do chefe e/ou cônjuge de família próximos ao local de moradia: nenhum dos dois membros apresenta laços familiares próximos, um dos dois apresenta laços familiares próximos, os dois apresentam laços familiares próximos;

- Participação do chefe de família e/ou cônjuge nas atividades da sua religião: nenhum dos dois membros participa, somente um dos dois participa, o chefe e o cônjuge participam;

- Tempo de moradia em Paranaguá do chefe de família: migrante recente $(<5$ anos), migrante antigo ( $>5$ anos), nascido em Paranaguá;

- O chefe de família é sindicalizado: sim, não.

Num primeiro momento, foram escolhidas 75 famílias de forma a ilustrar cada um dos tipos encontrados e distribuídas nas diferentes zonas da cidade, mas com uma concentração maior nas duas zonas e nos tipos mais precários. Essas 75 famílias foram objeto de entrevistas semidiretivas, a partir de um guia de informações elaborado no sentido dos problemas encontrados pelas famílias e as respostas dadas a eles em relação aos seguintes temas: alimentação, saúde, moradia, estrutura familiar residencial, relações familiares e extra familiares, aspectos da trajetória familiar, migratória e profissional, recursos financeiros, formas de sociabilidade.

Num segundo momento, foram selecionadas vinte famílias para serem acompanhadas ao longo de seis meses, por meio da observação participante, das práticas e estratégias de enfrentamento dos problemas cotidianos ligados à saúde, a partir de eventos concretos identificando a quais lógicas estas estratégias correspondiam; entrevistas aprofundadas gravadas sobre este tema foram igualmente realizadas nesta etapa da pesquisa. O processo de visitas semanais regulares permitiu a identificação de problemas de saúde, assim como o acompanhamento e a forma como foram interpretados e resolvidos (itinerários terapêuticos). Essa forma de acompanhamento dos itinerários colocou em evidência a importância e a pertinência da metodologia da observação participante, que permitiu trocas importantes e um olhar in situ sobre o processo da doença. Descrever os itinerários terapêuticos a partir dos primeiros sinais da doença até o seu término (havendo cura ou não) e suas conseqüências sobre as condições de vida e as transformações da vida cotidiana e familiar, não é tarefa fácil. O acompanhamento dos doentes do começo ao fim de seu itinerário, das escolhas realizadas, implica uma participação importante por parte do pesquisador durante um período suficientemente longo para permitir uma presença durável e consistente entre o pesquisador e as pessoas com as quais trabalha.

\section{Diversidade, pluralidade \\ e complexidade na busca por cuidados terapêuticos}

A procura de cuidados terapêuticos, por parte do indivíduo ou da família, origina-se de situações diversas, sendo a morbidade um fenômeno objetivo e subjetivo, não existindo uma demarcação nítida entre as variações da saúde e da doença. Um indivíduo pode sentir-se mais doente, abandonar mais precocemente suas atividades cotidianas, ausentar-se do trabalho por mais tempo, se sentir mais incomodado que outro com os mesmos sintomas objetivos 14 . Lenta ou bruscamente transita-se da "normalidade" ao "patológico", desencadeando um processo complexo, quanto à escolha do tipo de recurso a adotar, influenciado não só por fatores objetivos, mas também pelas representações que interferem na explicação da doença, na opção por determinado recurso e nos itinerários em busca de cuidados terapêuticos.

Os resultados aqui apresentados seguem a ordem de aprofundamento da análise, partin- 
do-se do quadro geral da cidade para as condutas individuais. Assim, os resultados do zoneamento e da estratificação social mostram a existência de uma grande diversidade e heterogeneidade no espaço urbano em matéria de ambiente físico, moradia, demografia e vida social. O zoneamento espacial 10 compreende cinco grandes zonas, cujas características descritivas se resumem da melhor zona em termos de crescimento espacial, infra-estrutura, serviços e condições de vida, que se situam no centro urbano, até as piores zonas como as Franjas e Ilha de Valadares (Figura 1). A estratificação social 13 comportou um modelo final de três estratos sócio-econômicos: superior (222 famílias, 35\% da população total), médio (240 famílias, 38\%), inferior (177 famílias, 28\%).

O confronto entre esses dois instrumentos de análise (Figura 2) demonstrou que mesmo existindo uma forte correlação entre o recorte espacial e a distribuição da população em função da posição na hierarquia social, os três estratos estão presentes em todas as zonas. A combinação dessas duas dimensões (espacial e social) constituiu o quadro geral de análise que a antropologia não pode se contentar para avaliar a pobreza e as desigualdades sociais, pois este não permite desvendar as condições e dificuldades individuais ou familiares cotidianas no acesso aos bens e serviços, na medida em que múltiplos fatores intervêm na vida cotidiana. Desta forma, a tipologia do "potencial de mobilização de recursos sociais”, permitiu avançar na aproximação das famílias a serem acompanhadas no seu cotidiano, sendo que foram encontrados três grandes tipos de situação que se caracterizam, sumariamente por:

- Tipo I: agrupa o maior número de famílias cuja estrutura permite uma maior possibilidade de mobilização de recursos intrafamiliares, com chefes e/ou cônjuge que possuem laços familiares próximos ao local de moradia, participam de atividades de sua religião, nasceram em Paranaguá e são sindicalizados. Apresentam todos os elementos para a mobilização de diferentes redes de solidariedade (cidade, bairro, parentesco, trabalho);

- Tipo II: o número das famílias cuja estrutura permite uma maior possibilidade de mobilização de recursos intrafamiliares diminui sensivelmente em relação ao nível anterior, chefes e/ou cônjuge que possuem laços familiares próximos ao local de moradia diminui igualmente, a maioria não possui laços familiares próximos ao local de moradia, diminui a participação em atividades da religião, o número de chefes migrantes aumenta consideravelmente em relação ao nível anterior e a de chefes sin- dicalizados diminui. Grupo de famílias já estabelecido na cidade, mas que apresenta dificuldades para mobilizar "recursos sociais" em praticamente todos os níveis;

- Tipo III: maior número de famílias cuja estrutura não permite a mobilização de recursos intrafamiliares e comunitários: não possuem laços familiares próximos ao local de moradia, não participam de atividades da religião, a maioria é de migrantes recentes, não sindicalizados. Grupo de famílias que acumula todos os fatores desfavoráveis em relação à mobilização de "recursos sociais".

Ainda nesse nível mais geral de análise, o estudo de Novakoski 15 quanto à utilização de serviços de saúde e as trajetórias terapêuticas, evidenciou disparidades espaciais e desigualdades sociais relacionadas aos aspectos sócioeconômicos. A trajetória terapêutica demonstrou-se diferenciada em função das queixas ou problemas de saúde serem considerados leves ou graves. Para a busca de recursos para solução de problemas leves (Figura 3), o estudo verificou que a automedicação é freqüentemente o primeiro recurso para 269 (88,2\%) famílias, diminuindo significativamente, como medidas subseqüentes. A procura de cuidados tradicionais é menos freqüente, mas predomina como segunda opção para 63 (46,2\%) entrevistados e $44(34,4 \%)$ recorrem a eles como terceira opção. A procura de serviços de saúde também aparece com menor freqüência, $181(61,8 \%)$ como segunda medida e para $68(23,2 \%)$ como terceira opção. Esta situação pode denotar que, ao longo da trajetória, parte dos problemas é solucionado.

A Figura 3 demonstra também que todas as famílias entrevistadas buscam algum tipo de solução para os episódios ou problemas de saúde, sendo que a maioria delas, 269 (80,5\%), recorrem à automedicação como primeira medida de solução de seus problemas; no caso de insucesso nesta etapa, 270 (80\%) procuram um segundo recurso, destacando-se os serviços formais de saúde; a utilização de uma terceira medida é adotada por $122(36,5 \%)$ casos, em relação às 334 famílias entrevistadas. Nessa medida, a diferença entre a busca de serviços de saúde e a procura de cuidados tradicionais é relativamente pequena.

O estudo aponta que a automedicação e o uso indiscriminado de medicamentos "bons para tudo e para todos", na solução de problemas de saúde, aparentemente leves e comuns, podem provocar resultados inesperados e desastrosos. Essa prática social alcança dimensões difíceis de estimar, mas pode revelar, além do aspecto cultural, a dificuldade de acesso aos 


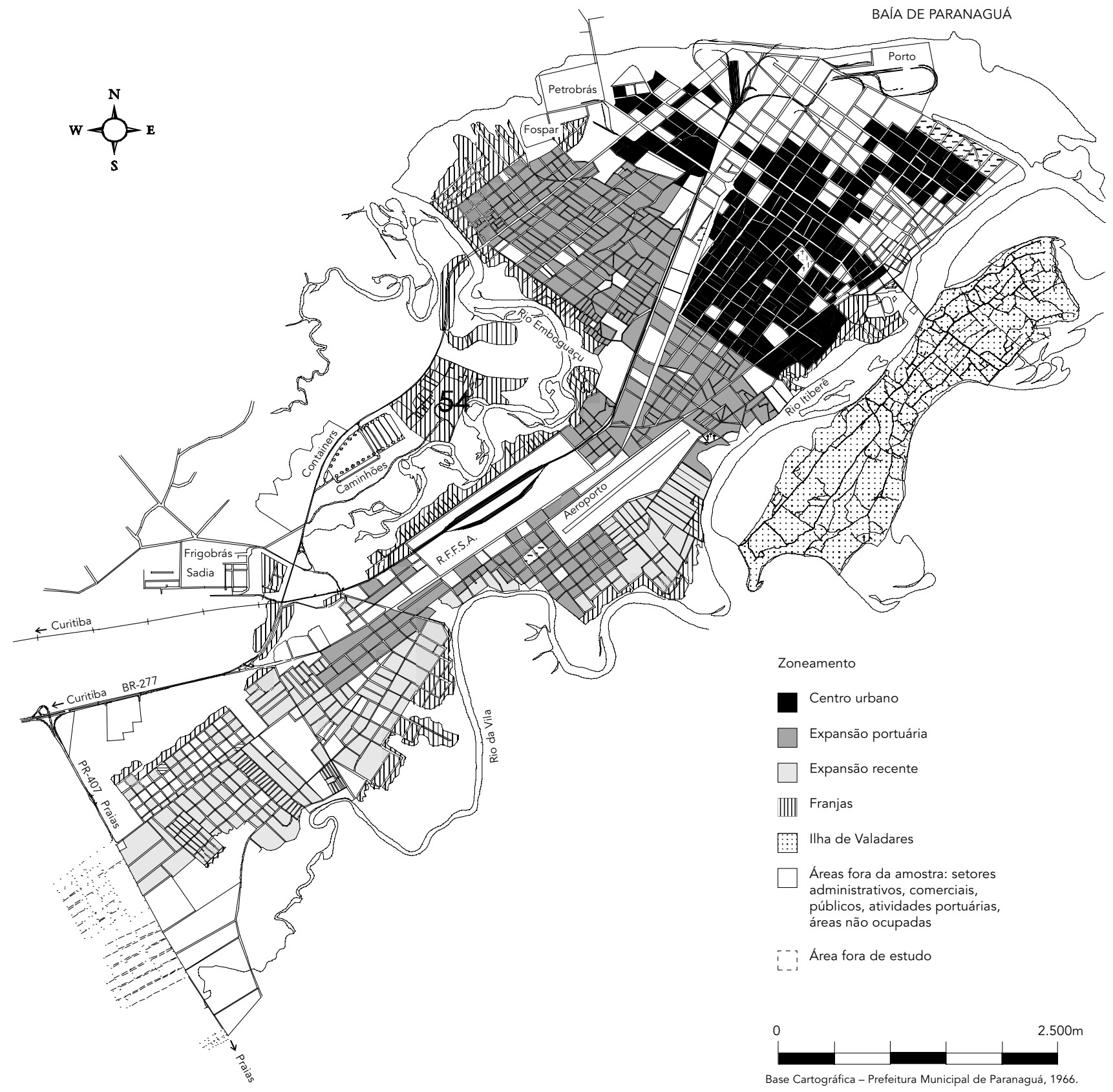

(C) Tatiana E. Gerhardt, Eleusis R. Nazareno, Lourdes E. R. Novakoski. Fonte: Gerhardt 2. 
Figura 2

Distribuição dos estratos sócio-econômicos de acordo com as diferentes zonas da cidade de Paranaguá,

Paraná, Brasil, 1996.

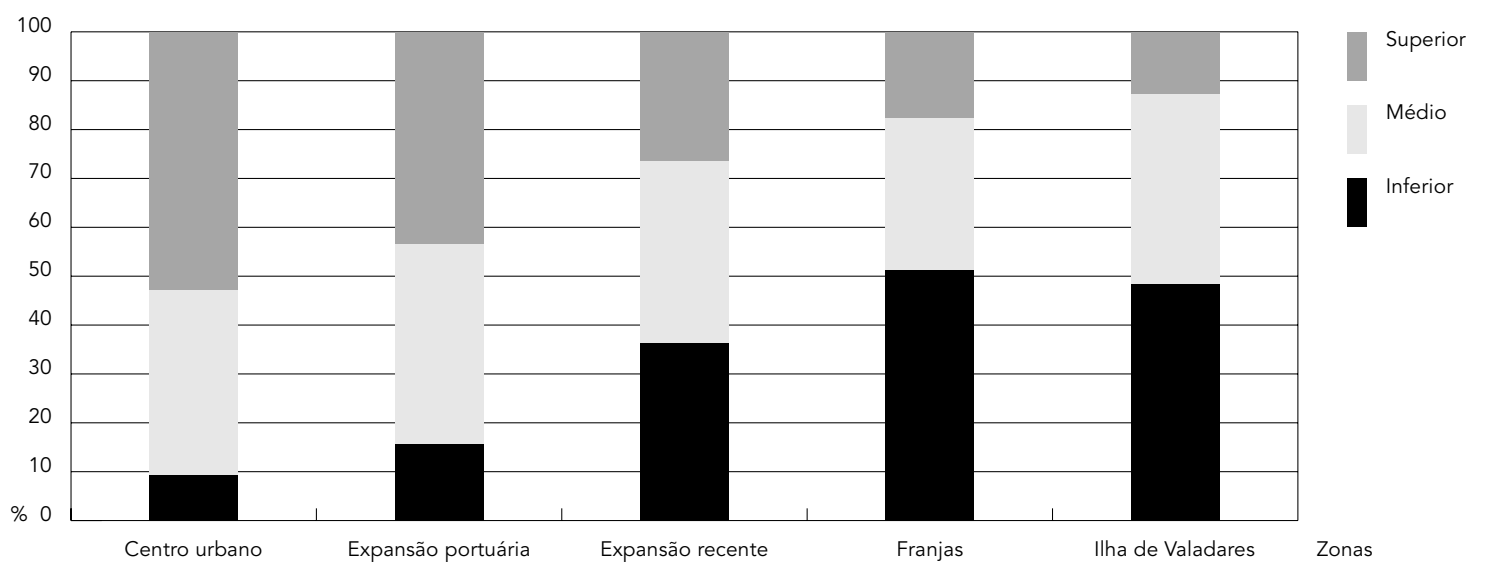

Fonte: Gerhardt 2.

$\chi^{2}=102,95 ; p=0,0$.

serviços de saúde, cuja oferta é heterogeneamente estruturada e distribuída, constituindo ela mesma, fator gerador de desigualdades. A análise destas variáveis por zonas e estratos sociais revelou que nas situações leves, à medida em que a prática da automedicação e a adoção de cuidados tradicionais aumentam em relação aos estratos médio e inferior, inversamente há diminuição na procura de serviços de saúde. Já para o estrato superior, a procura maior é nestes últimos.

Quanto aos recursos utilizados frente a episódios considerados graves (Figura 4), 326 (97,6\%) famílias costumam recorrer imediatamente ao atendimento médico, em serviços da rede pública, ambulatórios, pronto socorro, hospitais, consultórios médicos e clínicas. O estudo constata que em situações de gravidade diferenciada a busca de cuidados profissionais nos serviços de saúde está presente em todas as trajetórias, ainda que em momentos diferentes; isto não significa a resolutividade de todos os problemas, mas representa percentual elevado, considerando-se que, dos 326 que recorrem de imediato a esse tipo de cuidado, somente 36 (11\%) não tiveram seus problemas solucionados e continuaram a busca por outros recursos.

Os resultados deste estudo demonstram que as famílias assumem condutas diferentes diante de problemas de saúde considerados leves e graves. A diferenciação de situações leves e graves tem como referencial a experiência acumulada pela própria vivência de determinados episódios, os hábitos culturais transmitidos de uma geração para outra, o conhecimento incorporado pelo contato com profissionais da saúde, as mensagens veiculadas pelos meios de comunicação, a convivência e o intercâmbio de conhecimentos e experiências com amigos e vizinhos, eis o que determina a escolha de um ou outro tipo de recurso. Entretanto, não de forma linear como este estudo quantitativo pode demonstrar. Outros estudos têm demonstrado 1,3,4,5,6,7,8,16 que nesse processo é comum a simultaneidade de recursos utilizados. Desta forma, as questões aqui levantadas demandaram o desenvolvimento de um estudo qualitativo aprofundado, passando-se para outro nível de análise. Ilustra-se dessa forma, a contribuição da saúde pública para a antropologia, que pode por meio do enriquecimento de sua problemática formular questões e hipóteses de pesquisa a cada etapa, situando os estudos de caso em um contexto mais amplo.

Sendo assim, partindo dos resultados apresentados até o momento, Ilha de Valadares e Franjas foram as duas zonas escolhidas para o aprofundamento das questões envolvendo a busca terapêutica, por se distinguirem claramente no plano do ambiente físico, sanitário, social e cultural. A primeira zona, de ocupação mais antiga e cuja população é originária de pequenas comunidades de agricultores e pescadores da região, está ainda ligada à "cultura rural", ao mesmo tempo em que se beneficia do quadro de vida urbano. Neste sentido, o pa- 
Árvore de recursos terapêuticos utilizados para problemas considerados leves ou costumeiros pela população de Paranaguá, Paraná, Brasil.

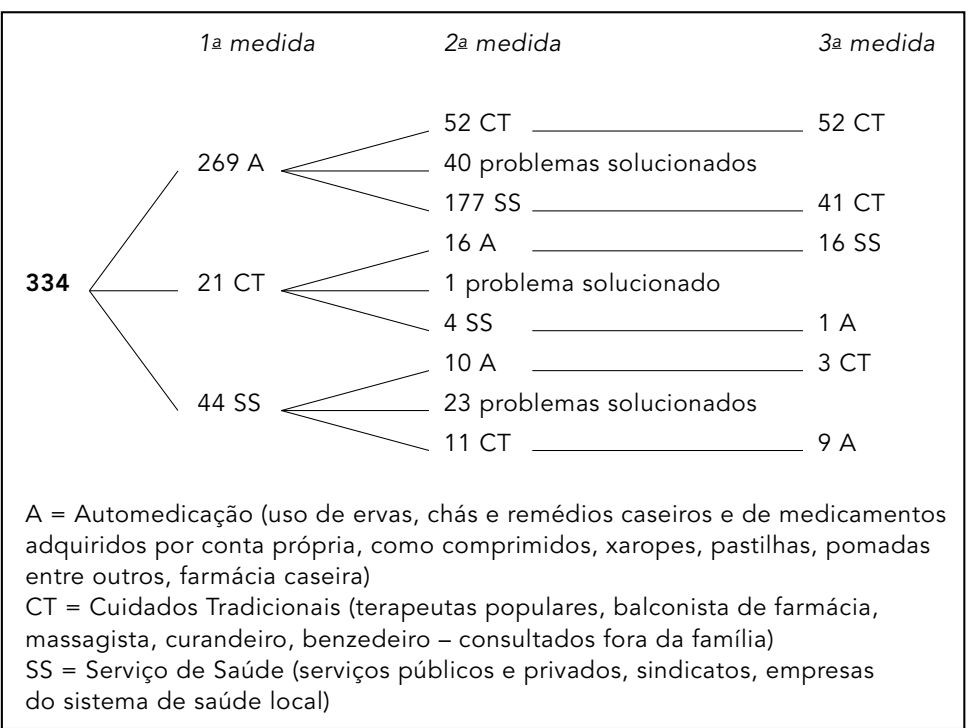

\section{Problemas leves}

Resfriado e gripe - 249- 41,0\%

Dor de cabeça - $169-27,8 \%$

Dor de barriga - $39-6,4 \%$

Febre - $37-6,1 \%$

Não especificado - $24-3,9 \%$

Demais problemas - $180-14,8 \%$

Fonte: Adaptado de Novakoski 15.

Figura 4

Árvore de recursos terapêuticos utilizados para problemas considerados graves pela população de Paranaguá, Paraná, Brasil.

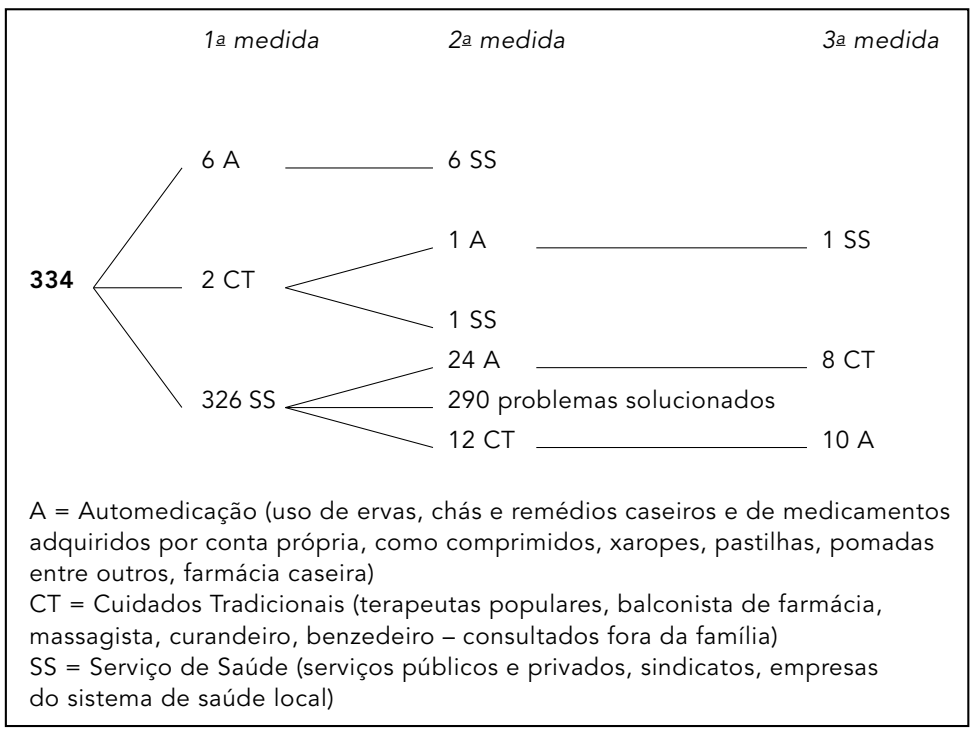

\section{Problemas graves}

Febre - 113-17,8\%

AIDS - $64-10,1 \%$

Câncer $-60-9,4 \%$

Dor forte e desconhecida -

$58-9,1 \%$

Diarréia - $41-6,5 \%$

Demais problemas - $305-47,0 \%$

Fonte: Adaptado de Novakoski 15. 
rentesco geograficamente próximo fornece às famílias um quadro econômico e social que lhes permite resistir, até um certo ponto, à precariedade material. Ele constitui o elemento mais estável da estrutura social. A segunda zona, as Franjas, de ocupação recente e cuja população é, na sua maioria, originária da própria cidade de Paranaguá, partilha muito mais a cultura urbana e encontra-se em uma situação de maior ruptura com o parentesco.

Sendo assim, ser pobre na Ilha de Valadares onde a rede de parentesco é próxima e os laços sociais intensos, conduz à formulação de estratégias de sobrevivência diferentes dos pobres que moram nas Franjas. O parentesco possui um papel importante entre essas famílias carentes na sobrevivência dos moradores de Valadares, o que já não acontece com os moradores das Franjas, que buscam no seio do núcleo familiar e da comunidade o desenvolvimento de estratégias de sobrevivência. A valorização da família e do parentesco entre os mais desfavorecidos é o resultado da forma como eles vivem suas próprias condições de vida, seus projetos, e de como eles se posicionam frente às outras categorias sociais. Neste sentido, a vida familiar e comunitária não está isolada, ela insere-se na dinâmica econômica e social da sociedade como um todo e na capacidade individual de integrar-se a ela.

Ainda, a precariedade do mercado de trabalho e a instabilidade do trabalho portuário são dificuldades importantes que boa parte da população de Paranaguá deve enfrentar. A informalidade confere aos chefes de família um estatuto que lhes oferece menos possibilidades de acumulação, mas trata-se de uma categoria interessante para a análise das situações de vida, pois faz intervir diferentes estratégias colocadas em prática pelos atores sociais. As zonas das Franjas e da Ilha de Valadares concentram o maior número de chefes de família que não possui trabalho formal, mas que tentam de alguma forma ganhar sua vida no dia-a-dia. Existe uma diversidade de situações em termos de procura de trabalho informal. Estratégias são colocadas em prática, particularmente apoiando-se em redes de troca e de entre-ajuda ou apelando a instituições de ajuda social (prefeitura, igrejas) que podem contribuir ao estabelecimento de relações de dependência em relação a estas instituições. De certa forma, além da ajuda material que essas instituições prestam, elas funcionam como agentes de integração, de socialização e de solidariedade para as populações mais carentes, porém esta ajuda não é gratuita, ela exige uma contrapartida, seja em termos monetários, seja em termos de fidelidade.
O acompanhamento da vida cotidiana de indivíduos e de suas famílias dessas zonas mostrou que as preocupações relativas à saúde não constituem uma prioridade em si mesmo, mas fazem parte de um todo maior de restrições cujas prioridades se expressam em termos de manutenção das condições de vida da família e da sua reprodução física e social.

A população residente nas duas zonas estudadas revela diferentes escolhas em termos de recursos terapêuticos: profissionais de saúde da rede de Atenção Básica, dos hospitais, de farmácias, benzedeiros, curandeiros e automedicação (medicamentos convencionais e utilização de ervas medicinais). Os indivíduos utilizam assim as diferentes opções existentes sucessivamente ou simultaneamente.

A busca de cuidados terapêuticos em Paranaguá revelou, em relação aos três tipos de "potencial de mobilização de recursos sociais", a existência de uma complexidade e pluralidade que uma abordagem quantitativa não é capaz de evidenciar. Encontrou-se quatro grandes situações em relação a essa busca de cuidados: (i) apoio social e enfrentamento da doença; (ii) exclusão social e enfrentamento da doença; (iii) saúde, religião e apoio social: “...se Deus quiser assim..."; (iv) clientelismo e enfrentamento da doença.

Ilustrando a pluralidade e complexidade dessas situações, toma-se o exemplo da primeira situação (apoio social e enfrentamento da doença) que, quantitativamente, se caracteriza por famílias que acumulam todos os fatores desfavoráveis em relação à mobilização de "recursos sociais" (Tipo III). Todavia, a análise qualitativa (observação participante e entrevistas) revelou outra realidade (Figura 5): famílias com capacidade comprometida em relação à reprodução física, devido a problemas como ausência ou instabilidade de emprego, dívidas importantes, alguns problemas de saúde e de moradia, mas com certa capacidade de reprodução social devido à ausência de problemas de conflitos familiares internos e externos, problemas de drogas, alcoolismo e prostituição na família, e com alta capacidade de mobilização de recursos familiares e comunitários. Esta última característica se deve ao fato de as mulheres possuírem uma ampla capacidade individual de desenvolver estratégias individuais e coletivas, por meio de uma rede intensa de entre-ajuda familiar e comunitária, mesmo o parentesco se situando distante geograficamente. A busca de cuidados terapêuticos nessa situação é ilustrada na Figura 5. A família 1 reside na zona das Franjas, mas possui uma rede de entre-ajuda familiar e comunitária muito inten- 
Figura 5

Exemplo de um itinerário terapêutico na situação de apoio social e enfrentamento da doença. Paranaguá, Paraná, Brasil, 1999.

\begin{tabular}{|c|c|c|c|c|c|c|}
\hline 1ㅇ dia & 2o dia & 3o dia & 4ㅇ dia & 5으 dia & 6o dia & Mês seguinte \\
\hline $\begin{array}{l}\text { Primeiros sintomas } \\
\downarrow \downarrow \\
\text { Chás com ervas } \\
\text { medicinais } \\
\downarrow \\
\text { PS próximo } \\
\text { (consulta) } \\
\qquad \\
\text { Tratamento } \\
\text { (medicamentos } \\
\text { e inalações; dis- } \\
\text { tribuídos entre } \\
\text { os } 4 \text { filhos; } \\
\text { "prevenção") }\end{array}$ & $\begin{array}{l}\text { Sintomas evoluem } \\
\text { PS outro } \\
\text { (consulta) } \\
\text { PA ("médicos } \\
\text { da capital") } \\
\quad \downarrow \\
\text { Tratamento } \\
\text { (medicamentos } \\
\text { e inalações) } \\
\quad \downarrow \\
\text { Chás com ervas } \\
\text { medicinais }\end{array}$ & $\begin{array}{l}\text { GAPER (Grupo de } \\
\text { Apoio a Pessoas } \\
\text { com Doenças } \\
\text { Respiratórias) } \\
\downarrow \\
\text { Pastoral da Criança } \\
\text { (vale-transporte) } \\
\downarrow \\
\text { Secretaria Muni- } \\
\text { cipal de Saúde } \\
\text { (encaminhamento } \\
\text { ao GAPER) } \\
\qquad \\
\text { Chás com ervas } \\
\text { medicinais }\end{array}$ & $\begin{array}{l}\text { Secretaria Muni- } \\
\text { cipal de Saúde } \\
\text { (encaminhamento } \\
\text { ao GAPER + } \\
\text { consulta) } \\
\downarrow \\
\text { PS da SMS (1/3 } \\
\text { medicamentos) } \\
\downarrow \\
\text { Farmácia do } \\
\text { sindicato (restante } \\
\text { dos medicamentos) }\end{array}$ & $\begin{array}{l}\text { Casa da avó na } \\
\text { Ilha de Valadares } \\
\quad \downarrow \\
\text { Vereadora (cesta } \\
\text { básica) } \\
\quad \downarrow \\
\text { GAPER (consulta } \\
\text { somente para o } \\
\text { mês seguinte) } \\
\quad \downarrow \\
\text { Medicamentos + } \\
\text { Chás com ervas } \\
\text { medicinais }\end{array}$ & $\begin{array}{l}\text { Melhora dos } \\
\text { sintomas } \\
\qquad \\
\text { Interrupção do } \\
\text { tratamento } \\
\text { (medicamentos e } \\
\text { inalações - farmácia } \\
\text { caseira) }\end{array}$ & $\begin{array}{l}\text { Sintomas recomeçam, } \\
\text { assim como a busca } \\
\text { terapêutica a partir } \\
\text { da mobilização dos } \\
\text { recursos sociais } \\
\text { disponíveis }\end{array}$ \\
\hline
\end{tabular}

Filha sob os cuidados de uma vizinha

Filha sob os cuidados da avó

Tipos de ajuda: conselhos, medicamentos, vale-transporte, cesta básica,

Tipos de ajuda: apoio material (moradia, alimentação); apoio contatos nos serviços de saúde, apoio religioso moral (conselhos, tomada de decisões, compartilhar informações); monitoramento da doença

\begin{tabular}{|c|c|c|c|c|c|c|c|c|c|c|c|c|c|c|c|c|c|c|}
\hline \multirow[b]{3}{*}{ Alim } & \multirow[b]{3}{*}{ Mor } & \multicolumn{9}{|c|}{ Tipos de problemas ressentidos e expressos } & \multicolumn{5}{|c|}{ Recursos mobilizados } & \multicolumn{3}{|c|}{ Papel } \\
\hline & & \multicolumn{5}{|c|}{ Reprodução física } & \multicolumn{4}{|c|}{ Reprodução social } & \multicolumn{2}{|c|}{ Familiares } & \multicolumn{3}{|c|}{ Externos } & \multirow[b]{2}{*}{ Relig } & \multirow[b]{2}{*}{$\mathrm{H}$} & \multirow[b]{2}{*}{ M } \\
\hline & & $\mathrm{IM}$ & $S^{3}$ & AT & IT & Div & $\mathrm{CF}$ & CFI & DP & Alcoo & $A D$ & $A R$ & VD & VR & Trab & & & \\
\hline
\end{tabular}

Alim = alimentação; Mor = moradia; IM = instabilidade moradia; S = saúde; AT = ausência trabalho; IT = instabilidade trabalho;

$\mathrm{Div}=$ dividas financeiras; $\mathrm{CF}=$ conflitos familiares; $\mathrm{CFI}=$ conflitos familiares internos; $\mathrm{DP}=$ drogas, prostituição; Alcoo = alcoolismos;

$\mathrm{AD}=$ ajuda dada; $\mathrm{AR}=$ ajuda recebida; $\mathrm{VD}=$ vizinha dado; $\mathrm{VR}=$ vizinha recebido; Trab = trabalho; Relig = religião.

Pontuação: 0 = inexistente; 1 = presente; 2 = fortemente presente.

Situação síntese:

- Capacidade comprometida em relação a reprodução física, devido a problemas como ausência ou instabilidade de emprego, dívidas importantes, alguns problemas de saúde e de moradia;

- Certa capacidade de reprodução social, devido à ausência de problemas de conflitos familiares internos e externos problemas de drogas, alcoolismo e prostituição na família;

- Alta mobilização de recursos familiares e comunitários (conforme figura abaixo).

Redes de entre-ajuda terapêutica entre famílias aparentadas e não-aparentadas.

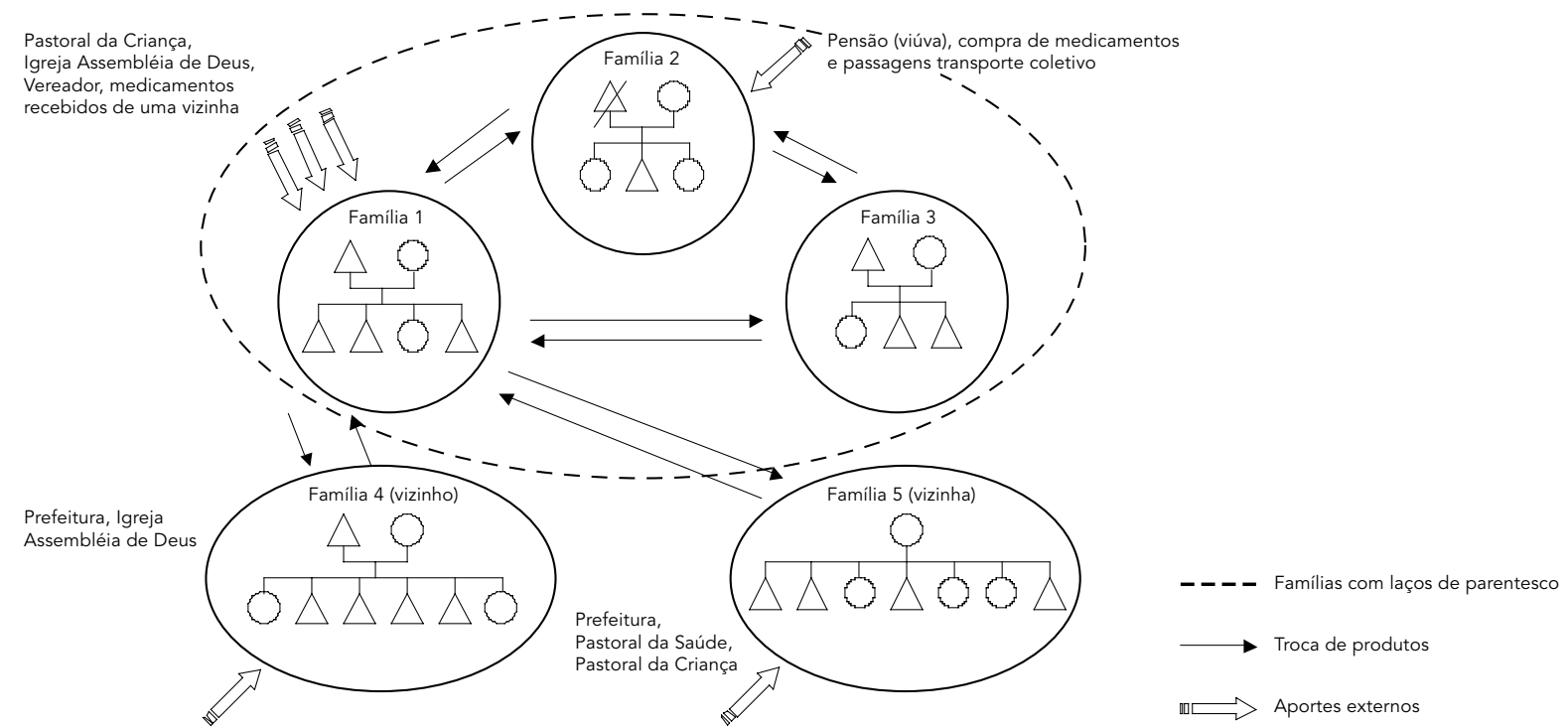


sa. As famílias aparentadas moram distantes geograficamente sem que isso impeça a mobilização de apoio em caso de doença (por exemplo, a mobilização da família 2 , residente na Ilha de Valadares, durante um certo período de tempo para cuidar dos filhos doentes). Da mesma forma, simultaneamente, mobiliza apoio em entidades religiosas diversas (católica e pentecostais) como forma de garantir algum suprimento em termos de medicamentos ou alimentos. Além disso, a busca terapêutica envolve a automedicação e a utilização de vários serviços de saúde da rede de Atenção Básica local, independente da sua localização. Sua forma de enfrentar e de minimizar o impacto dos eventos imprevistos sobre a saúde dos membros de sua família depende em muito da sua capacidade em tomar decisões individuais, ao mesmo tempo em que mobiliza recursos coletivos, mesmo devendo mobilizar outros recursos que permitam percorrer toda a cidade para tal.

A segunda situação (exclusão social e enfrentamento da doença), ilustra exatamente a situação inversa: quantitativamente, se caracteriza por famílias que acumulam todos os fatores favoráveis em relação à mobilização de "recursos sociais" (Tipo I). Todavia, a análise qualitativa revelou famílias com baixa capacidade de reprodução física, devido a importantes problemas materiais e físicos (moradia, emprego, saúde, alimentação); baixa capacidade de reprodução social, devido a importantes problemas de conflitos familiares internos e externos, problemas de drogas, alcoolismo e prostituição na família; certa capacidade de mobilização de recursos familiares (mas com dificuldades), não mobilização de recursos externos à família, muitas vezes por incapacidade da mãe e não participação do pai. A não mobilização de recursos familiares (apesar de terem a rede de parentesco situada próxima geograficamente) e comunitários se deve ao fato de que as mulheres apresentam uma situação social extremamente frágil, a ponto de se encontrarem psicologicamente depressivas, fisicamente debilitadas e socialmente sozinhas. Este estado não permite a mobilização de nenhum recurso familiar ou comunitário, fato que repercute de forma bastante negativa na saúde dos indivíduos que compõem o núcleo familiar, deixando muitas vezes antever um comportamento "passivo" diante de condutas a serem tomadas. Léa é um exemplo dessa situação: ela reside na Ilha de Valadares e sua rede de entre-ajuda, se é que existe uma, é bastante reduzida. Ela é católica e privilegia a utilização de serviços de saúde, ao mesmo tempo em que busca cuidado terapêutico junto a curandeiros e benzedeiros.
Os intensos conflitos familiares e com seu parentesco, sua doença crônica que a impede fisicamente de tomar em mãos sua própria vida, a impede ainda mais de mobilizar outros tipos de recursos, sobretudo comunitários, e de minimizar a vulnerabilidade das crianças frente à doença, mesmo as mais simples (parasitoses, problemas de pele, infecções respiratórias).

Essas duas situações mostram que as forma de enfrentar a doença e de minimizar os impactos de eventos imprevistos sobre a saúde dos indivíduos deve-se muito à capacidade individual de tomar decisões, ao mesmo tempo em que se mobiliza redes coletivas de entreajuda e outros tipos de recursos sociais, mesmo havendo influência das concepções de saúde, da doença e do corpo (não abordados neste texto), e dos recursos de saúde disponíveis. A maneira como colocam em prática o conhecimento ou o modo pelos quais eles enfrentam os eventos (neste caso, a doença), pode vir a perturbar o frágil equilíbrio de suas vidas cotidianas. Como observado por Fonseca $17 \mathrm{em}$ outros contextos, em Paranaguá, são as mulheres, que mesmo em contextos de grandes dificuldades materiais, agem como atores de suas situações de vida.

Os itinerários e escolhas terapêuticas foram analisados, portanto, não somente como um estado crônico ou agudo, mas como o resultado de um processo. A saúde se insere nas estratégias individuais e familiares, ao mesmo tempo em que se apóia em diferentes tipos de recursos coletivos. Os itinerários observados ilustram a prática cotidiana de recursos frente a doença, onde diferentes estratégias incorporam diferentes escolhas e diferentes alternativas que não se excluem e que são, ao contrário, plurais. Eles revelam um processo no qual se articula o individual e o coletivo nas estratégias de enfrentamento colocadas em prática por indivíduos capazes de mobilizar recursos materiais e imateriais.

O que se observa igualmente, é que as atividades ligadas à saúde se desenvolvem em casa, com atividades que compreendem não somente os primeiros cuidados, mas a avaliação do estado de saúde e as decisões sobre o tipo de recurso a ser mobilizado. Seja qual for o grau de dificuldade econômica, este não é o único em questão quando se trata de saúde. Às dificuldades de acesso econômico e geográfico acrescenta-se o contexto cultural, que não se resume às crenças e condutas individuais. Envolvem também o diálogo entre os diferentes atores, fato primordial para a compreensão da natureza do problema e a sua solução. Igualmente, o espaço intervém seguramente no aces- 
so aos serviços de saúde, mas torna-se secundário quando se trata de resolver um problema para as famílias que possuem certa capacidade em desenvolver estratégias. As conseqüências da situação econômica, espacial e ambiental num mesmo local não são as mesmas para todos os indivíduos. Como observou Raynaut 16,18,19, ao mesmo tempo em que alguns perdem o rumo e encontram-se presos a um ciclo dificilmente reversível, outros, ao contrário, conseguem reagir e, às vezes, tirar vantagens das possibilidades que lhes são oferecidas.

\section{Considerações finais}

Com base nessas informações algumas considerações podem ser feitas, sobretudo em relação à existência de uma pluralidade de fatores que intervêm na escolha dos indivíduos, que através de um estudo aprofundado pode ser colocado em evidência. Também igualmente importante, a abordagem interdisciplinar, pano de fundo desta pesquisa, permitiu a interface entre as diferentes disciplinas, momentos cruciais para conduzir o aprofundamento da problemática, como na interpretação, análise e contextualização dos resultados.

O que fica evidenciado neste estudo é que além dos limites das condições materiais de vida, os indivíduos constroem as estratégias de vida de acordo com suas capacidades, suas histórias de vida e suas experiências individuais. A capacidade de ação dos indivíduos em Paranaguá permite questionamentos sobre as relações entre condições de vida e estado de saúde, relação que não possui sempre uma determinação direta, sendo modulada pelo savoir faire das mulheres em situação de pobreza (capacidade de adaptação ao consumo restritivo e de ter múltiplas relações), portanto pelas características do sujeito, do problema e da percepção de saúde e da configuração do sistema de saúde.

As alternativas de escolha terapêutica também são múltiplas e vão desde a "informal" (automedicação, conselho ou tratamento recomendado por parente, amigo, vizinho...), passando pela "popular" (curandeiros, benzedeiros, "vovós”...), até a "profissional”. Cada uma possui vantagens e desvantagens e são escolhidas em função das disponibilidades circunstanciais e das explicações culturalmente aceitas pelo indivíduo e seu grupo. As estruturas sociais utilizadas e as estratégias desenvolvidas em Paranaguá compreendem as relações familiares e de vizinhança (desempenhando o papel principal), a integração a redes de solidariedade or- ganizadas em torno das igrejas, a integração em redes sociais e políticas de clientelismo que podem dar acesso às cestas básicas. Sendo assim, num país como o Brasil, fortemente marcado pela diversidade cultural, pela mobilidade, esses valores de solidariedade, de ajuda, as relações clientelistas de proteção do dependente e de fidelidade ao patrão desempenham um papel essencial na construção dos laços sociais entre os indivíduos.

A diversidade e a pluralidade de fatores que estão presentes na saúde e na doença são ainda portadores de múltiplos sentidos: pluralidade de condutas, pluralidade de terapeutas, pluralidade de etiologias (causas), pluralidade de percepções e de visões de mundo. Os resultados deste estudo não nos deixam, portanto, pensar na doença, suas causas e seu tratamento de forma linear onde só há lugar para uma forma de resolução do problema. Torna-se evidente a necessidade de considerar que dentro do contexto no qual está inserida a vida cotidiana dos indivíduos, existe uma possibilidade, um espaço, uma margem onde os indivíduos, sendo atores de suas próprias vidas, desenvolvem estratégias de enfrentamento aos problemas que lhes são impostos e, desta forma, constroem suas próprias situações de vida. Essas estratégias incluem as modalidades de manejo do quadro de vida material e social restritivo e expressam as diferentes capacidades individuais.

Por outro lado, o nível de análise macrossocial trouxe contribuições importantes, permitindo construir um quadro geral dentro do qual evoluem as diferentes situações existentes. Para compreender a relação entre itinerário terapêutico, saúde e pobreza, algumas vezes nítida e em outros casos pouco expressiva, foi necessário situar as estratégias e as lógicas utilizadas pelas populações nos diferentes níveis onde se desenvolvem.

Desta forma, algumas questões levantadas no nível mais global foram retomadas: as zonas da cidade não são homogêneas, pois dentro delas "co-residem" diferentes categorias sociais que, mesmo se situando em um mesmo contexto espacial, dispõem de meios distintos para encontrar respostas aos problemas que se apresentam. A saúde dos indivíduos expressa o impacto dos problemas materiais sobre o corpo, e permite, de um certo modo, uma leitura destas relações. Por outro lado, existem mecanismos de regulação ou de perturbação da saúde e da doença que são de ordem social e cultural, a saber: papel das relações sociais (familiares e comunitárias); solidariedades que as fortalecem ou conflitos que as dividem - como mediadores entre o indivíduo e seu ambiente 
físico. Os comportamentos e opiniões de indivíduos dependem em grande parte das estruturas nas quais eles estão inseridos e do sistema de valores e normas veiculados pelo meio social ao qual fazem referência, e que governam as relações entre ambiente-saúde-sociedade; conseqüências dos comportamentos individuais em relação às desordens corporais (físicas), de acordo com as representações do corpo e da doença e as respostas propostas pelas diferentes possibilidades de cuidados em saúde.

Sendo assim, a partir do momento em que não nos contentamos em saber que o estado de saúde de uma população é um reflexo "passivo" de suas condições de vida materiais, é indispensável levar em conta as respostas sociais que são dadas aos problemas que se apresentam, sob a forma de gestão social, não exclusivamente da saúde e da doença, mas também da vida cotidiana como um todo. Isto implica um esforço de compreensão dos problemas ligados à saúde e a capacidade de mobilização de "recursos sociais", capazes de dar um tipo de resposta aos problemas encontrados, e das trajetórias sociais que levam os indivíduos a se encontrarem em tal situação, que vão muito além do modelo biomédico.

Os itinerários terapêuticos dependem de estratégias complexas fundamentadas na elaboração de relações sociais e de práticas de inserção social. Como também fora apontado por Alves \& Souza 6 e Raynaut 20, a contribuição da antropologia se dá na interpretação destes comportamentos: não simplesmente como estraté- gias práticas, funcionais, materiais (respostas adaptativas à carência de recursos, redes espontâneas de "seguro social"), mas na evidência de que essas relações sociais existem independentemente das funções práticas que podem cumprir nas situações de crise, ou seja, também por meio da linguagem simbólica de construção de relações sociais, na essência não biológica, que contribuem para remodelar e a recriar o espaço de recursos no interior do qual se resolvem os problemas de ordem biológica. O imaterial (neste caso uma concepção das relações sociais) reveste, portanto, uma eficácia material (biológica). Assim, o estado de saúde dos indivíduos (determinante para grupos sociais se reproduzirem fisicamente) está vinculado a fatores imateriais como os objetivos e os valores sociais que estruturam as relações interpessoais, refletindo também a posição que o indivíduo ocupa dentro da estrutura social e econômica de Paranaguá. No entanto, cada um - indivíduo, família, grupo - mantém um espaço de atuação próprio que lhe permite intervir como ator da sua própria existência: reinterpretando as condições externas às quais ele está submetido e elaborando a sua situação de vi$d a$ : realidade existencial quotidiana à qual ele impõe, com mais ou menos força, conforme os casos, a sua visão. Ele elabora assim, no decorrer da sua história pessoal, sua própria experiência de sujeito: consciência e olhar distanciado sobre o que, em torno dele, é do domínio do material e do imaterial 20.

\section{Resumo}

As práticas e estratégias da população de baixa renda no enfrentamento de problemas cotidianos, sobretudo em relação à procura de cuidados em saúde, são analisadas por meio dos itinerários terapêuticos. Desvendar as formas de enfrentamento dessa população, no que se refere ao seu processo saúde-doença, implica identificar as estratégias individuais e coletivas e os significados destas dinâmicas sociais relacionadas direta ou indiretamente com a saúde. A busca de cuidados terapêuticos é aqui descrita e analisada em relação às práticas sócio-culturais de saúde em termos dos caminhos percorridos pelo indivíduo, na tentativa de solucionar seus problemas de saúde. Para tanto, o estudo indica uma opção metodológica (interdiscipli-

nar e plurimetodologia) e conceitual relacionando conceitos de práticas, estratégias, situações de vida e saúde. Parte-se do princípio de que as formas de enfrentamento dos problemas de saúde demandam a compreensão das estratégias colocadas em prática em um processo de (re)apropriação e (re)construção de saberes. Igualmente importante é a identificação das redes de apoio social, assim como da capacidade individual em mobilizar tais recursos. O reconhecimento dessas práticas permite o (re)direcionamento das ações em Saúde Coletiva.

Assistência à Saúde; Fatores Sócio-econômicos; Resolução de Problemas 


\section{Referências}

1. Massé R. Culture et santé publique. Les contributions de l'anthropologie à la prévention et à la promotion de la santé. Montréal: Gaëtan Morin Éditeur; 1995.

2. Gerhardt TE. Anthropologie et santé publique: approche interdisciplinaire. Pauvreté, situations de vie et santé à Paranaguá, Paraná, Brésil [Tese de Doutorado]. Bordeaux: Université de Bordeaux $2 ; 2000$.

3. Benoist J. Soigner au pluriel. Essais sur le pluralisme médical. Paris: Karthala; 1996.

4. Fassin D. Entre pouvoir et maladie en Afrique. Paris: PUF; 1992.

5. Fassin D. Pauvreté, urbanisation et santé. Les inégalités d'accès aux soins dans la banlieue de Dakar. Psychopathologie Africaine 1987; 21:155-76.

6. Alves PCB, Souza IM. Escolha e avaliação de tratamento para problemas de saúde: considerações sobre o itinerário terapêutico. In: Rabelo MC, Alves PCB, Souza IMA, organizadores. Experiência de doença e narrativa. Rio de Janeiro: Editora Fiocruz; 1999. p. 125-38.

7. Rabelo MC. Religião e cura: algumas reflexões sobre a experiência religiosa das classes populares urbanas. Cad Saúde Pública 1993; 9:316-25.

8. Alves PC. A experiência da enfermidade: considerações teóricas. Cad Saúde Pública 1993; 9:263-71.

9. Caneparo SC, Carneiro SMM, Cerdeira PC, Costa LJM, Gerhardt TE, Godoy AMG, et al. Espaço urbano, situações de vida e saúde na Cidade de Paranaguá: relato preliminar de uma prática interdisciplinar. Cadernos de Desenvolvimento e Meio Ambiente 1996; 3:35-48.

10. Gerhardt TE, Nazareno ER, Novakoski LER. Heterogeneidades e homogeneidades do quadro de vida urbano de Paranaguá. Curitiba: Doutorado em Meio Ambiente e Desenvolvimento, Universidade Federal do Paraná; 1996.

11. Gerhardt TE, Nazareno ER. Diálogo entre a epidemiologia e a antropologia nas questões de saúde. In: Raynaut C, Zanoni M, Lana PC, Floriani D, Ferreira AD, Andriguetto Jr. JM, organizadores. Desenvolvimento e meio ambiente: em busca da interdisciplinaridade. Pesquisas urbanas e rurais. Curitiba: Editora UFPR/Organização das Nações Unidas para Educação, a Ciência e a Cultura; 2002. p. 103-25.
12. Raynaut C, Damasceno AF. Metodologia do diagnóstico interdisciplinar em Paranaguá: a construção de um quadro de trabalho comum. In: Raynaut C, Zanoni M, Lana PC, Floriani D, Ferreira $\mathrm{AD}$, Andriguetto Jr. JM, organizadores. Desenvolvimento e meio ambiente: em busca da interdisciplinaridade. Pesquisas urbanas e rurais. Curitiba: Editora UFPR/Organização das Nações Unidas para Educação, a Ciência e a Cultura; 2002. p. 29-41.

13. Gerhardt TE, Nazareno ER, Novakoski LER. Desigualdades sociais e situações de vida em Paranaguá. Curitiba: Doutorado em Meio Ambiente e Desenvolvimento, Universidade Federal do Paraná; 1997.

14. Lebrão ML. Estudos de morbidade. São Paulo: Edusp; 1997.

15. Novakoski LE. As desigualdades socioambientais e a utilização de serviços de saúde [Tese de Doutorado]. Curitiba: Doutorado em Meio Ambiente e Desenvolvimento, Universidade Federal do Paraná; 1999.

16. Raynaut C. Inégalités économiques et solidarités sociales. In: Fassin D, Jaffre Y, editors. Sociétés, développement et santé. Paris: Ellipses/Aupelf; 1990. p. 136-54.

17. Fonseca C. Ser mulher, mãe e pobre. In: Del Priori M, Bassanezi C, organizadores. História das mulheres no Brasil. São Paulo: Editora da Unesp/ Contexto; 1997. p. 510-53.

18. Raynaut C, Gerhardt TE, Nazareno ER. Pauvreté, inégalités économiques et disparités de santé: conditions de vie et stratégies d'acteurs. Revue Face à Face. Regards sur la Santé 2002; 4:3-20. http://www.ssd.u-bordeuax2.fr/faf/ (acessado em 05/Dez/2002).

19. Raynaut C. Interdisciplinaridade e promoção da saúde: o papel da antropologia. Algumas idéias simples a partir de experiências africanas e brasileiras. Rev Bras Epidemiol 2002; 5 Suppl 1:43-55.

20. Raynaut C. L'anthropologie de la santé: carrefour de questionnements. L'humain et le naturel, l'individuel et le social. Ethnologies Comparées 2001; 3. http://alor.univ-montp3.fr/cerce/revue.htm/ (acessado em 05/Dez/2002).

Recebido em 04/Out/2005

Versão final reapresentada em 03/Abr/2006

Aprovado em 17/Abr/2006 